\title{
Repeat Duration
}

National Cancer Institute

\section{Source}

National Cancer Institute. Repeat Duration. NCI Thesaurus. Code C93647.

The period of time over which the event or activity is repeated. 